\title{
Adnexal torsion in the first trimester of a spontaneous pregnancy: detorsion and oophoropexy
}

\author{
Burcu Dincgez, ${ }^{1}$ Murat Bozkurt, ${ }^{2}$ Banu Öndes, ${ }^{1}$ Ayşe Ender Yumru, ${ }^{1}$ Cengiz Yumru, ${ }^{3}$
}

Keywords: Adnexal diseases, pregnancy, torsion, ovary, pregnancy trimester, first

\begin{abstract}
Introduction: Adnexal torsion is a rare cause of acute abdominal pain during pregnancy. In this case report, we present a case of adnexal torsion during the first trimester of pregnancy and its treatment.
\end{abstract}

Case Presentation: A 28-year old, gravida 1, para 0 patient at 9 weeks gestational age presented to the antenatal clinic with acute abdominal pain in the right lower-abdominal quadrant. The patient was diagnosed with torsion of the right adnexa during pregnancy, and detorsion was performed. The patient was followed throughout the course of pregnancy. She delivered a healthy baby at term by caesarian section. During the caesarian section, both of the adnexa were observed to be normal.

Conclusions: With acute abdominal pain, especially in the lower-abdominal quadrant during pregnancy, adnexal pathologies should be considered. Diagnosis of adnexal torsion during the first trimester of pregnancy is often missed due to the nonspecific clinical features and uncommon objective findings. Although surgical intervention should be considered to treat pregnant women suffering from adnexal torsion regardless of the gestational week, abdominal surgery carries some risks to the pregnant woman and unborn fetus.

${ }^{1}$ Taksim Education and Research Hospital, Department of Obstetrics and Gynecology, Istanbul, Turkey

${ }^{2}$ Universal Hospitals Group, Department of Obstetrics and Gynecology, Malatya, Turkey

${ }^{3}$ Taksim Education and Research Hospital, Department of Anesthesiology and Critical Care, Istanbul, Turkey

\section{Introduction}

Adnexal torsion is a surgical gynecologic emergency with a rare occurrence during pregnancy. The incidence during pregnancy is 1 in 5000 , and it occurs more frequently in the first trimester in patients that that underwent treatment for infertility with in vitro fertilization (IVF) or ovarian stimulation. ${ }^{1}$ Physicians should be alert for adnexal

Please cite this paper as: Dincgez B, Bozkurt M, Öndes B, Yumru AE, Yumru C. Adnexal torsion in the first trimester of a spontaneous pregnancy: detorsion and oophoropexy. Proc Obstet Gynecol. 2013;3(3): Article 4 [ 7 p.]. Available from: http://ir.uiowa.edu/pog/. Free full text article.

Corresponding author: Murat Bozkurt, MD. Ismetpaşa cad. Cemal Gürsel Mah. Sefa Apt. No:113/26 44000 MALATYA /TURKEY. Tel: 904222382828/1546- 905322279072. Fax: 904222382600. e-mail jindrmb@yahoo.com.

Financial Disclosure: The authors report no conflict of interest including no connection to any biotechnology manufacturer, pharmaceutical company or other commercial entity.

Received, 16 May 2013; accepted, 30 November 2013; POG in Press, 9 December 2013.

Copyright: (C) 2013 Dincgez et al. This is an open-access article distributed under the terms of the Creative Commons Attribution License, which permits unrestricted use, distribution, and reproduction in any medium, provided the original author and source are credited. 
torsion when a patient presenting with acute onset abdominal pain, nausea, and vomiting has undergone assisted reproduction with controlled ovarian hyperstimulation. Presence of an ovarian or tubal pathology is remarkable in its etiology. ${ }^{2}$ One of the important pathologies is ovarian hyperstimulation, which often leads to ovarian torsion. During pregnancy, the clinical symptoms are non-specific and could be confused with other acute abdominal conditions such as acute appendicitis, ruptured corpus luteum cyst, adnexal abscess, ovarian hyperstimulation, urinary obstruction, and ectopic pregnancy. Absence of an arterial flow in the Doppler sonography may be used as a supporting diagnostic finding. ${ }^{3}$ Detorsion of the twisted adnexa should be primarily considered for the treatment. Organ preservation surgery is crucial to prevent infertility and continuity of the pregnancy in the reproductive age groups. Early diagnosis of the adnexal torsion is especially important for organ preservation surgery. ${ }^{4}$

\section{Case Presentation}

A 28-year old, gravida 1, para 0 patient at 9 weeks gestational age was admitted to the emergency service with severe acute abdominal pain in the right lower-abdominal quadrant. The pain has been persisting for 4-5 hours. The patient described her pain as nonradiating, sharp, and 9 out of 10 in severity. There was no history of vaginal bleeding or discharge, nausea, vomiting, fever, diarrhea, constipation, fever, or urinary complaints. Her general and gynecologic history was normal. She had regular antenatal checkups. No significant past medical and surgical history were noted.

On physical examination, the patient was found to be exquisitely tender to palpation with rebound tenderness. Her vital signs were remarkable, with a blood pressure of $80 / 50 \mathrm{~mm} \mathrm{Hg}$ and a pulse of 96 beats $/ \mathrm{min}$. Abdominal examination revealed a palpable right lower quadrant mass at the level of the umbilicus, with rebound, tenderness, defense and peritoneal signs. Pelvic examination revealed a 9-week sized uterus, with a closed cervix, and a tender nearly $7-8 \mathrm{~cm}$ right adnexal mass.

Laboratory results were normal. Transabdominal sonography performed at the bedside demonstrated a normal single fetus in utero with a CRL measurement compatible with 9 weeks gestational age. There was a $3 \mathrm{~cm}$ subserous myoma in the fundal region. In the right adnexa, a large, $7 \mathrm{~cm} \times 6$ $\mathrm{cm}$, heterogenous hypoechoic mass with irregular margin was detected (Image 1). The left ovary appeared normal, and no free fluid was observed in the cul-de-sac. Other intraabdominal solid organs were normal. Both color and power Doppler showed markedly reduced flow to the right ovary, suggesting ovarian torsion. The left ovary appeared to be normal with adequate vascular blood flow.

After no relief with IV narcotics, the patient was taken to the operating room for urgent laparotomy. Operative findings demonstrated a massively enlarged right ovary with widespread hemorrhage. The ovary had a dark bluish-ischemic appearance and was found to be extremely friable. The ovary 
and tuba appeared to have twisted around its pedicle three times. After detorsion the ovarian pedicle, vascular blood flow resumed and the ovary returned to its normal color and showed no signs of hemorrhage or necrosis. The following postoperative day, a repeated control Doppler imaging study was done to assess blood flow to the ovary.
Results of color-flow Doppler were normal and the patient was discharged home. The patient had no further problems during the pregnancy. She had no complications or recurrence of ovarian torsion during this pregnancy. She delivered a healthy infant at 39 weeks 5 days of gestation.

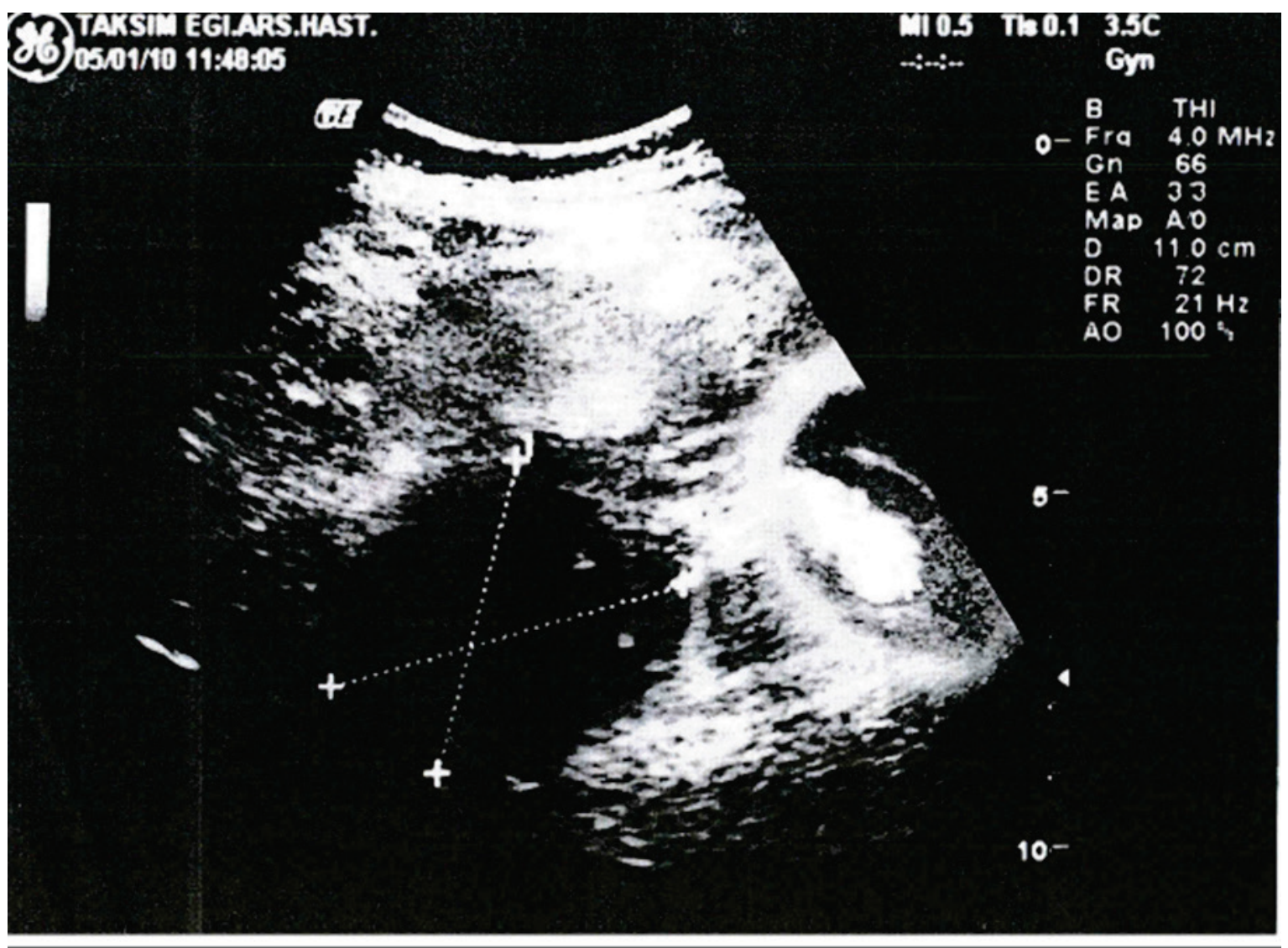

Image 1: In the right adnexa, a large, $7 \mathrm{~cm} \times 6 \mathrm{~cm}$, heterogenous hypoechoic mass with irregular margins was detected. The fetus is seen on the left side of the cyst.

\section{Discussion}

Adnexal torsion is a rare cause of surgical gynecologic emergency during pregnancy. The incidence of ovarian torsion increases 5-fold during pregnancy to approximately 1 per 5000 pregnancies. The most common cause of adnexal torsion during the pregnancy is a corpus luteum cyst, which usually regresses spontaneously in the second trimester. For this reason, adnexal 
torsion most commonly occurs in the first trimester, sometimes in the second, and rarely in the third trimester. ${ }^{5}$ Torsion of the ovaries may be by total or partial rotation of the adnexa around its vascular axis or pedicle. Ovarian torsion may occur by total or partial rotation of the adnexa around its vascular axis or pedicle. Any ovarian pathologies which increase the size of the ovary and length of the pedicle, and also pregnancy that enlarges and rotates the uterus, lead to changes in the position of the ovary. These physiologic and pathological conditions are important factors of ovarian torsion. $^{6}$ During the early stage of the torsion, lymphatic or venous blockade could cause massive enlargement of the ovary with continued arterial inflow. If untreated, arterial stasis can occur, potentially leading to hemorrhagic infarction and necrosis of the ovarian stroma. Because the sigmoid colon limits the mobility of the left ovary, ovarian torsion most commonly occurs in the right adnexa as in our case. ${ }^{7}$

Diagnosis of the adnexal torsion during the first trimester can sometimes be difficult due to the nonspecific clinical features and uncommon objective findings. The most common clinical presentation is acute onset of severe colic pain in the unilateral lowerquadrant. Other findings and symptoms are vomiting $(76 \%)$ and palpate abdominal mass (82\%). ${ }^{8}$ Another common response to visceral and deep somatic nociception is decreased heart rate and blood pressure. ${ }^{9}$ Our patient was admitted with severe right lower quadrant abdominal pain, which had persisted for 4-5 hours, with a right palpated adnexal mass without emesis.
When diagnosing ovarian torsion, ultrasound is the first choice for imaging and will demonstrate unilateral ovarian enlargement which contains solid, cystic or complex components with or without fluid collections in the pouch of Douglas. Also, color Doppler sonography will often demonstrate an enlarged ovary without perfusion of the parenchyma. ${ }^{10}$ The disadvantages of the sonographic examination is that the ovaries are sometimes difficult to visualize in the second and third trimesters of pregnancy because they are displaced from the pelvis by the enlarging uterus. On color Doppler imaging, absence of intraparenchymal ovarian blood flow could suggest ovarian torsion. Decreased blood flow to the ovary does not always rule out the possibility of ovarian torsion. This matter depends on the stage of the torsion and the degree of vascular compression. During the early stage of torsion, the venous and lymphatic systems will be affected. Arterial flow may only be decreased at this stage. This is termed as incomplete torsion. During the late stage of torsion, arterial blood flow decreases and arterial stasis can occur allowing necrosis and hemorrhagic infarction.

Surgical treatment of the adnexal torsion may be necessary. The risk factors of any surgery during pregnancy include gestational age, coexistence of other chronic diseases and poor condition of the fetus. Most adnexal torsion occurs in the first trimester of the pregnancy. With the use of modern anesthetic techniques, the risk of fetal loss is quite rare. Although the most adnexal torsion occurs in the first trimester, surgery during the second and third trimester carries the risk of premature labor. ${ }^{11}$ 
Minimally invasive surgical techniques used for the treatment of an adnexal torsion have becoming increasingly popular. Laparoscopic evaluation with simple detorsion is increasingly the preferred surgical approach for the treatment of an ovarian torsion, because it allows the ovary to remain intact. ${ }^{4,6}$ In addition, this procedure allows the physician to drain cysts, examine possible underlying causes of the torsion, and manually detorse the ovary. ${ }^{12-14}$

Standard surgical techniques include laparotomy with detorsion or salpingooophorectomy. Organ preservation surgery is crucial in terms of continuity of the pregnancy. ${ }^{1}$ Oelsener reported that they performed detorsion by laparotomy in all of 40 torsion cases regardless of the macroscopic appearance. ${ }^{15}$ This method was also recommended by the other studies. Taskin et al. supported these studies by reporting that there was not a correlation between macroscopic appearance of the torsioned adnexa and degree of microscopic ischemia in their animal study. ${ }^{16}$

In our case, the right adnexa was detorsioned and oophoropexy was performed in order to prevent recurrence by laparotomy. Performing oophoropexy in order to eliminate retorsion is controversial in cases where flows return to normal. Although some studies advocate oophoropexy in order to prevent recurrence, there is not a consensus on this issue. ${ }^{17-19}$

In this case report, we presented the successful treatment without any complications of an adnexal torsion during the first trimester of the pregnancy. Also in our case, making an early diagnosis led to organ preservation surgery, which retained fertility.

\section{Conclusion}

Adnexal torsion is an urgent surgical gynecologic emergency. Pregnancy can also play an important role in the etiology of adnexal torsion. Acute onset of lower quadrant abdominal pain, an adnexal mass and clinical evidence of peritonitis during the pregnancy must alert the physician to possible adnexal torsion. Color Doppler sonography must be performed and both of the adnexa should be scan carefully in the pregnant woman for the preoperative diagnosis of torsion. Surgical techniques should be considered in the development of the adnexal torsion regardless of the gestational age. Making an early diagnosis is very important to perform organ preservation surgery to prevent infertility and normal continuity of the pregnancy.

\section{References}

1. Mancuso A, Broccio G, Angio LG, Pirri V. Adnexal torsion in pregnancy. Acta Obstet Gynecol Scand. 1997 Jan;76(1):83-4. PubMed PMID: 9033251.

2. Bayer Al, Wiskind AK. Adnexal torsion: can the adnexa be saved? Am J Obstet Gynecol. 1994 Dec;171(6):1506-10; discussion 1510-1. PubMed PMID: 7802059 . 
3. Lee EJ, Kwon HC, Joo HJ, Suh JH, Fleischer AC. Diagnosis of ovarian torsion with color Doppler sonography: depiction of twisted vascular pedicle. $\mathrm{J}$ Ultrasound Med. 1998 Feb;17(2):83-9. PubMed PMID: 9527577.

4. Chapron C, Capella-Allouc S, Dubuisson JB. Treatment of adnexal torsion using operative laparoscopy. Hum Reprod. 1996 May;11(5):9981003.

http://dx.doi.org/10.1093/oxfordjournals. humrep.a019338. PubMed PMID: 8671377.

5. Ventolini G, Hunter L, Drollinger D, Hurd W.W. Ovarian torsion during pregnancy. Resident and Staff Physician 2007; 12 (1):1- 4 .

6. Boswell KM, Silverberg KM. Recurrence of ovarian torsion in a multiple pregnancy: conservative management via transabdominal ultrasound-guided ovarian cyst aspiration. Fertil Steril. 2010 Oct;94(5):1910.e1-3. doi: 10.1016/j.fertnstert.2010.03.020. Epub 2010 Apr 18. Review. PubMed PMID: 20403591.

7. Phupong $V$, Intharasakda $P$. Twisted fallopian tube in pregnancy: a case report. BMC Pregnancy Childbirth. 2001;1(1):5.

http://dx.doi.org/10.1186/1471-2393-1-5. PubMed PMID: 11716791; PubMed Central PMCID: PMC59895.

8. Kruger E, Heller DS. Adnexal torsion. A clinicopathologic review of 31 cases. J Reprod Med. 1999 Feb;44(2):71-5. PubMed PMID: 10853434.

9. Cavun S, Goktalay G, Millington WR. The hypotension evoked by visceral nociception is mediated by delta opioid receptors in the periaqueductal gray. Brain Res. 2004 Sep 3;1019(1-2):23745.

http://dx.doi.org/10.1016/j.brainres.2004. 06.003. PubMed PMID: 15306258.
10. Van Voorhis BJ, Schwaiger J, Syrop $\mathrm{CH}$, Chapler FK. Early diagnosis of ovarian torsion by color Doppler ultrasonography. Fertil Steril. 1992 Jul;58(1):215-7. PubMed PMID: 1624012.

11. Visser BC, Glasgow RE, Mulvihill KK, Mulvihill SJ. Safety and timing of nonobstetric abdominal surgery in pregnancy. Dig Surg. 2001;18(5):40917.

http://dx.doi.org/10.1159/000050183.

PubMed PMID: 11721118.

12. Rackow BW, Patrizio P. Successful pregnancy complicated by early and late adnexal torsion after in vitro fertilization. Fertil Steril. 2007 Mar;87(3):697.e9-12. Epub 2006 Dec 4. PubMed PMID: 17141765.

13. Pinto AB, Ratts VS, Williams DB, Keller $\mathrm{SL}$, Odem RR. Reduction of ovarian torsion 1 week after embryo transfer in a patient with bilateral hyperstimulated ovaries. Fertil Steril. 2001 Aug;76(2):403-6. http://dx.doi.org/10.1016/S00150282(01)01910-0. PubMed PMID: 11476798.

14. Pan HS, Huang LW, Lee CY, Hwang JL, Chang JZ. Ovarian pregnancy torsion. Arch Gynecol Obstet. 2004 Sep;270(2):119-21. Epub 2004 Feb 28. http://dx.doi.org/10.1007/s00404-0020407-3. PubMed PMID: 14997324.

15. Oelsner G, Shashar D. Adnexal torsion. Clin Obstet Gynecol. 2006 Sep;49(3):459-63.

http://dx.doi.org/10.1097/00003081200609000-00006. PubMed PMID: 16885653. 
16. Taskin O, Birincioglu M, Aydin A, Buhur A, Burak F, Yilmaz I, Wheeler JM. The effects of twisted ischaemic adnexa managed by detorsion on ovarian viability and histology: an ischaemiareperfusion rodent model. Hum Reprod. 1998

Oct;13(10):2823-7. http://dx.doi.org/10.1093/humrep/13.10. 2823. PubMed PMID: 9804239.

17. Gökaslan H. Clinical approach to adnexal masses in adolescence. Turk Arch Ped 2011; 46 (1): 111-4.

18. Djavadian D, Braendle W, Jaenicke F. Laparoscopic oophoropexy for the treatment of recurrent torsion of the adnexa in pregnancy: case report and review. Fertil Steril. 2004 Oct;82(4):933-

6. http://dx.doi.org/10.1016/j.fertnstert.200 4.03.048. PubMed PMID: 15482773.

19. Nagel TC, Sebastian J, Malo JW. Oophoropexy to prevent sequential or recurrent torsion. J Am Assoc Gynecol Laparosc. $1997 \quad$ Aug;4(4):495-8. http://dx.doi.org/10.1016/S10743804(05)80046-5. PubMed PMID: 9224587. 